Research Notes

\title{
Social Stratification Principles in Santa Claus, Tooth Fairy and Easter Bunny: A Content Analysis
}

\author{
Toni Y. Sims-Muhammad, D.A.H. \\ Associate Professor of Social Sciences Allen University Columbia, South Carolina 29204, USA
}

Article history

Received: 03-02-2019

Revised: 08-06-2019

Accepted: 20-07-2019

Email: tmuhammad@allenuniversity.edu

\begin{abstract}
This paper is a content analysis about social stratification principles in popular culture fairytale characters Santa Claus, Tooth fairy and Easter bunny. Specifically, this paper explores how these fairytale characters may contribute to an entitlement identification construct of the African American child. The researcher argues that there are three major components of social stratification portrayed by the fairytale characters (1) ideas about money/wealth, (2) success and (3) the processes to obtain money/wealth and success. Utilizing content analysis, three of most popular portrayed narratives (short stories and songs) Santa Claus, Tooth Fairy and Easter Bunny were analyzed. Findings indicate that each fairytale contains inferred meanings about money/wealth, success and process to obtain them.
\end{abstract}

Keywords: Social Stratification, African American Children, Black Children, Education, Socialization, Social Class, Santa Claus, Easter Bunny, Tooth Fairy, Model Minority Child, Popular Culture

\section{Introduction}

Many parents and children like the fairytale characters Santa Claus, Tooth fairy and Easter Bunny. The gifts, "free" money and all the chocolate and eggs you can eat. It seems so innocent. Because of the popular portrayals of these fairytale characters, some African Americans are engaged by, as well as participate in narratives about money/wealth, success and processes employed by these characters. So what concepts, constructs, messages and meanings about money/wealth, success and process do Santa Claus, Tooth Fairy and Easter Bunny contain? And what does it mean for the African American child's identification/orientation of wealth and success? Compounded with the fragile financial state of many African Americans is the fact that Nielsen forecast yearly how African Americans have the highest holiday spending of all ethnic groups in the U.S. (Nielsen Company, 2018).

In a society where African Americans face critical challenges to secure income, wealth, education, debt, financial advancement, it is imperative that early factors contributing to a child's identification/orientation be examined. An appropriate place to begin is with fairytales. Many fairytales are associated with holidays that originate from European identification/orientation (culture). This European culture according to the critical race theory is rooted in the promotion of success as outgrowths of superiority through race, sex, and class position. Inversely, this narrative is promoted in mainstream mass media as a function of social identity and aligns with in-group favoritism (Vinney, 2018).

Many scholars note that American children are exposed to fairytales with mixed and confusing messages about money, wealth and success (Vissing, 2008; Lusted, 2009; The Red Menace, 2011; Woolley and Ghossainy, 2013). However, African American children, unlike their white counterparts, exposure may be problematic because they face multiple socio-cultural political challenges for upward mobility within the U.S. social stratification system. According to critical race theory, African American identification/orientation must not ignore these factors as they may foster pseudo-permanent sociological/pyschological characteristics (Vinney, 2018; Ambert, 1997). Further, it argues that "while race as a notion is a social construction and not rooted in biology, it has had real, tangible effects on African Americans and other people of color. This is noted specifically in terms of economic assets, education, and professional opportunities, as well as encounters with the legal system" (Bodenheimer, 2019).

Therefore, Santa Claus, Tooth fairy and Easter Bunny were selected due to their ultra-popular presence in mainstream society and because they are well known purveyors of social stratification as well as their potential to impact African American children perceptions, awareness and understanding about entitlement and empowerment. 


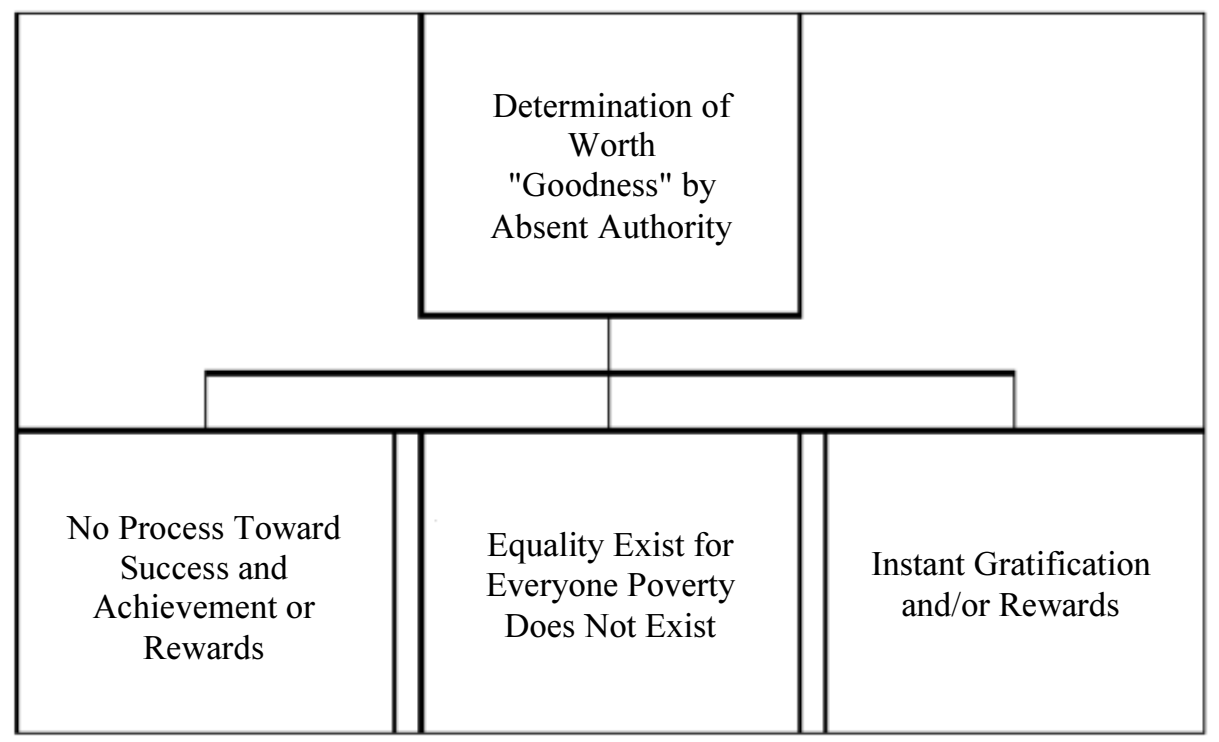

Fig. 1: Theory of class orientation and popular connections between fairytales

If African American financial conditions are a conundrum of long-term duplicitous negative social class contradictions, realities and poverty, then it may have some origin in fairytale narratives. Moreover, I propose the following $-\mathrm{a}$ theory of class orientation (class orientation theory) which postulates that popular culture icons, portrayals and perspectives can influence ideas about (1) money and wealth, (2) success and (3) the processes to obtain them which may impact critical awareness and outlook about status obtainment and empowerment see Fig. 1.

While limited data exist (Manosevitz, 1976; Principe and Smith, 2008; Strouse et al., 2018) about the impact of fairytale characters on children, parents and teachers may rely on them to transmit cultural traditions, ideas and values -not considering their potential empowerment inhibiting effect and entitlement implication. Particularly for African American children, these effects and implications may be damaging and undermine attempts to achieve individual and generational assets. Social identity theory is the framework for this analysis of social stratification. It argues that social identity is built on three key cognitive components: social categorization, social identification/orientation and social comparison. This analysis focuses on the component social identification/orientation as the fairytales and characters represent an ideal social status type, reflective of success (Vinney, 2018).

\section{Methodology}

The methodology employed in this theoretical discussion was content analysis. Specifically, popular songs and a script about the fairytales and characters Santa Claus, Tooth Fairy and Easter Bunny were examined for components of social stratification (1) ideas about money and wealth, (2) success and (3) the processes to obtain them. Content analysis research produces an account of social reality that makes sense of phenomenon based on critical data narratives containing rich interpretations of social life. Content analysis provides insight into the way people actively construct and find meaning in their world and has a long and distinguished history within the social sciences (Babbie, 2016; Crossman, 2019).

To this end, the most popular mainstream songs associated with and portrayed about Santa Claus, and Easter Bunny and the most popular short story about Tooth Fairy were reviewed. Unfortunately, Tooth Fairy does not have a popular song; however, its story embodies social stratification principles. The songs/story were analyzed for the following aspects:

- Money/Wealth: Do the fairytales characters possess unlimited money and ability to afford gifts?

- Success: Do the fairytale characters have special powers/position/status?

- Process: How did these fairytale characters get their success?

Another essential key to this analysis involves operationalizing social stratification. According to Macionis (2018) social stratification is rooted in fourprinciples:

- Social stratification is a trait of society, not simply a reflection of individual differences

- Social stratification persists over generations

- Social stratification is universal but variable

- Social stratification involves not just inequality but beliefs 
Macionis (2018) notes that the knowledge and understanding of these social stratification principles reflect one's social class and the degree of wealth or poverty in the society. Principle one notes that success is best measured by group and institution achievements and attainment. There is no need to pine away about pulling oneself up by the bootstraps. Participating in the system can more effectively change group and institutional poverty, poor education and low socioeconomic status. Furthermore, this principle of social stratification notes that there is a system of privilege and class operating in the United States (Perrucci and Wysong, 2008). Usually, one must be a part of the system to effect the most change. This principle may illustrate that African American children be taught how crucial it is that they become a part of the system. Then, they have the most effective orientation tools to carve out a space and place that challenges and changes their fate in society. The second social stratification principle addresses the issue of how social stratification is transferred between generations. A simple way to restate this principle is that just as one can inherit wealth, one can inherit poverty. Children can inherit poverty in several ways including the psychological binds and mind set, cultural attitudes, perceptions and beliefs, i.e. the culture of poverty and actions/practices (Perrucci and Wysong, 2008).

The third social stratification principle notes that social stratification exists everywhere in the United States. However, it exists in multiple and varying degrees (Perrucci and Wysong, 2008). Therefore, can Santa Claus, Easter bunny or tooth fairy accurately portray equality to children from different socio-economic backgrounds? The answer is no. The answer is no because children's socio-economic background is a result of their parent's socio-economic background. This means that the fairytale character is actually the parent or adult figure and provides or purchases what they can afford. Of course, when children compare gifts they might wonder whether the fairytale figure loves them, treats them all equally/fairly, or if they were worthy, deserving or good enough? Another way to apply this principle is to examine the fairytale characters' portrayal as great givers to everyone in the world versus the reality of social/global stratification. Children may not realize the extent of poverty that exists throughout the society or the world. Through these fairytales, children may be led to believe that everyone is equal and receives the same rewards. Once children become adults, they realize the deception but may become to disillusioned to overcome the system. Many youth from the Occupy Wall Street Movement noted that once they became conscious about social stratification (inequality) in real life, this disillusionment became their source of inspiration to disrupt and destroy the system (Schneider, 2011).

The fourth social stratification principle is probably the most fundamental principle --beliefs. Beliefs address the core understanding about why we either seek to be a part of the system --if we can see ourselves as elements of change -- or if we are content with our ranking or place in the system (Perrucci and Wysong, 2008). This principle addresses our perception of the system and if we believe, there is something wrong with the system. For example, if one does not believe there is something wrong with the system then they may be more likely to accept the system as it is, their place in it and abdicate their role/responsibility to change it.

Moreover, compounding the identification with these fairytales is that some African American children may also receive supplemental multifaceted reinforcement about social stratification through mass media. Mass Media is described as electronic/print forms of verbal and non-verbal communications that relay specific meanings and messages - intended to influence the values, ideas and beliefs of groups over large territories. These forms included but are not limited to: (1) Electronic: television, movies, music (video), radio, internet and (2) Print: newspapers, magazines, books.

Mass Media portrayals can compound socialization about money, success and the process involved to obtain them-intentionally or unintentionally, by the bombardment of mixed, unclear and misleading messages. For example, shows such as The Jeffersons, an African American couple/family struggles to overcome extreme/abject poverty and achieve a measure of success through hard work and dedication are rarely portrayed on mainstream television. Shows that feature families struggling with day-to- day survival, such as Good Times are also gone. The Cosby Show featured excellent examples of teaching children about the principles of social stratification. One particular episode addressed a child's understanding of their parent's money. Heathcliff Huxtable (dad) promptly corrects Vanessa (daughter), stating that, "your mother and I are rich, you have nothing." (Cosby Show, 2007). The television show Blackish is the latest to profile as African American family that addresses various issues regarding social stratification.

Overall, mass media portrayals contain excessive amounts of materialism lead with advertisements messages that one can have whatever they want, whenever they want it, void of actions and processes. And, modern day shows such as Love \& Hip Hop; Basketball Wives, and Real Housewives perpetuate even more stereotypes and false narratives about success and the process to obtain wealth. Simply put, there are insufficient mass media portrayals that acknowledge the role of parents as primary providers-the persons responsible for the children needs and wants. Portrayals hardly ever reflect the intricate actions/processes that success requires, in addition to the hard work, sacrifice and dedication to obtain measures of material goods and/or service. Regardless of the portrayal type there 
seems to be insufficient portrayals that balance problematic portrayals about social stratification for African American children. Again and again, portrayls fail to provide sufficient positive and informative identification and orientation for thinking, action and behavior that lead to empowerment.

\section{Findings: Santa Claus Rewards and Processes}

Santa Claus with his long white beard and jolly demeanor is the patron saint of the holiday season. However, how might children perceive Santa Claus -as it pertains to identification/orientation about social stratification? For this study, the following song was analyzed:

\author{
You better watch out \\ You better not cry \\ Better not pout \\ I'm telling you why \\ Santa Claus is coming to town \\ He's making a list \\ And checking it twice; \\ Gonna find out \\ Who's naughty and nice \\ Santa Claus is coming to town \\ He sees you when you're sleeping \\ He knows when you're awake \\ He knows if you've been bad or good \\ So be good for goodness sake! \\ O! You better watch out! \\ You better not cry Better not pout \\ I'm telling you why \\ Santa Claus is coming to town \\ Santa Claus is coming to town \\ (Coots and Gillespie, 1932)
}

The song analysis reveals the following identification and orientation about social stratification as shown in Table 1. This analysis reveals the following identification and orientation about social stratification that can be associated with the Santa Claus are:

- Santa represents the privileged class and gives to the good. The privileged class gives to the good i.e. those in the higher social class. Therefore, summed up below
- Santa's Money/Wealth: The fairytale character gives to all based on simple individual personality characteristics and factors

- Santa's Success: The fairytale character special powers/position/status is rooted in dominate group race and sex characteristics; therefore, granting automatic class privilege

- Santa's Process: Reinforced and assigned due to mainstream popular portrayals and association with higher authority/major religious holiday

\section{Findings: Easter Bunny Rewards and Processes}

German settlers introduced the Easter bunny during the 1700 's. Children were led to believe that if they were good that the Easter bunny would give them a nest of colored eggs. The Easter bunny also knew who was good and who was bad. Upon analysis, this might imply that the bigger your reward the better you must be and are - as it pertains to identification/orientation about social stratification. For this study, the following song was analyzed:

\author{
Here comes Peter Cottontail, Hoppin' down \\ the bunny trail \\ Hippity, hoppity, Easter's on its way \\ Bringin' every girl and boy \\ Baskets full of Easter joy \\ Things to make your Easter bright and gay \\ Try to do the things you should \\ Maybe if you're extra good \\ He'll roll lots of Easter eggs your way
}

This analysis reveals:

- Easter Bunny Money/Wealth: The fairytale character gives to all based on simple individual personality characteristics and unrefined competitive factors, i.e., Easter egg hunt

- Easter Bunny Success: The fairytale character special powers/position/status rooted in control over the possession of goods and distribution

- Easter Bunny Process: Reinforced and assigned due to mainstream popular portrayals and association with higher authority/major religious holiday

Table 1: Social stratification and social class perspectives of the fairytale character -- santa claus

\begin{tabular}{ll}
\hline The character gives to everyone. & The character is wealthy or rich. \\
\hline The character knows who you are and what you do. & The character has super powers. \\
The character gives equally to all. & Everyone is rewarded in the same manner. \\
The character gives only to those that are good. & Those who receive more rewards are better than \\
& those who receive less rewards. \\
The character is a saint. & The character is like God. \\
The character is a natural giver. & The character expects nothing in return. \\
If the character is a male- & Males are giving. \\
If the character is white- & Whites are giving. \\
If the character is big- & Big people are giving.
\end{tabular}




\section{Findings: Tooth Fairy Rewards and Processes}

In many households, Tooth Fairy operates under a cover of darkness, coming to visit after a child loses what are commonly called "baby teeth." Parents help perpetuate the fantasy by showing their children how to place the lost tooth under their sleeping pillow or in a special holder or pillow made just for Tooth Fairy. Then, Tooth Fairy visits during the middle of the night, exchanging the tooth for a gift or monetary reward (Wurtzel, 2006). For this study, the following story was analyzed.

\section{The legend and myth of the Tooth Fairy is a delightful part of our modern family culture. Kids dream about receiving a special gift or money from this charming, magical fairy. \\ Adults fondly remember the Tooth Fairy as a wonderful childhood fantasy of their youth and they pass on the mystery and charm to their own young children (Finley, 1992).}

The inquisitive child might begin to wonder, why does a winged being want my tooth? What will the tooth fairy do with all the teeth collected? Where does the tooth fairy get the money left in place of the tooth? The adult knows that the tooth fairy does not exist, knows that the tooth fairy does not want the child's tooth and knows that the reward associated with losing a tooth is misleading. Certainly, one should not expect a reward for losing a limb. Finley (1992) discusses the social class and social stratification issue in this way. Every time a child loses a tooth and places it under the pillow at night, Tooth Fairy turns up. Somehow, Tooth Fairy gets into our houses, finds a way to our rooms, sneaks money under our heads -where Tooth Fairy gets the money is never addressed-and then sneaks away without so much as a concern. But, the original tooth fairy was not always a tooth fairy. In fact, he spent the first 300 years of his career not giving gifts to kids but breaking into people's houses and stealing teeth they already had in their mouths and making jewelry from them (Finley, 1992).
Thus, the Analysis Reveals

- Tooth Fairy Money/Wealth: The fairytale character gives to all based on a required individual sacrifice of limited or little value.

- Tooth Fairy Success: The fairytale character special powers/position/status rooted in ability to give a reward and determine worth of the sacrifice.

- Tooth Fairy Process: Reinforced and assigned due to primary care takers, secondary child care providers and supported by a year-round ongoing tooth pool.

\section{Analysis and Conclusion}

Exposure to Santa Claus, Tooth fairy and Easter Bunny may present far too many intended and unintended consequences as indicated in the Table 2. Moreover, the theory of social stratification orientation posits that popular culture icons, portrayals and perspectives may influence ideas about (1) money and wealth, (2) success and (3) the processes to obtain them; therefore, inhibiting critical awareness and reflection about status obtainment and empowerment. Many scholars, educators and parents would agree that fairytales could be used to teach lessons, ideas and instill values and pride in children. These fairytales, however, also entail many powerful meritocracy and aristocracy messages, ideas and perspectives. In addition, institutional discrimination and institutional prejudice continue to exist throughout many institutions in American society impacting the socioeconomic empowerment of African Americans.

Therefore, African American children must have a social stratification and social class perspective that stresses the relevance of meritocracy variables for success. Albeit, African American success depends on the African American child's success and for that success to occur the African American child must understand (1) income and wealth, (how to earn money, work smarter not harder, how to save money and how to invest money), (2) success (to negotiate life's challenges and obstacles with responsibility, beneficence and justice) and (3) the processes to obtain them (education, skill development, ethics).

Table 2: Intended/Unintended Consequences of Exposure

\section{Exposed}

Uncertain attitude about money and

purpose/usefulness of money

Disassociate money and success with a process
Uneasiness about concept of good and bad as it relates to rewards

Unreasonable expectations for rewards

\footnotetext{
Not Exposed

Knowledge about money and purpose/usefulness Associate money and success with a process
}

Clearer understanding about good and bad as it relates to rewards Reasonable and flexible expectations for rewards and receiving and giving things 
Storytelling, myths and adages have historically played a role in the African American experience because they instilled a sense of pride, courage and strength (Banks-Wallace, 2002). They contained powerful messages of awareness, responsibility and empowerment, not only representing what African American had but what they hoped to obtain (Hamlet, 2011). Santa Claus, Tooth fairy and Easter bunny hardly reflect these messages and adults may not be aware of the possible social class and social stratification meanings associated with the fairy tale and the fairy tale character until they become adults (Deas, 2011).

African American children should learn about factors that determine generational wealth and may require a more robust environment that speaks/represents a more culturally relevant truth about social stratification and the aristocratic and meritocracy aspects of the society. African America children must be taught that things do not just happen without some direct human cause, i.e., human cause is responsible for gifts under the tree, human cause is responsible for money under the pillow and human cause is responsible for Easter eggs.

Moreover, (Fong, 2002) notes that one of the most distinct features of a successful minority group is their propensity towards business ownership-entrepreneurship. Because money is the basis of socioeconomic development, money must be a teaching component toward self-empowerment and community development. Furthermore, children represent the future and what they learn now affects their future, as well as their family/community/state/nation success. It is crucial that parents realize the significance of these factors and lay a solid financial education foundation. This foundation can provide children with the resources and tools that are needed to achieve greater overall empowerment. Final points for consideration are offered below:

- Address the African American child's perception of these fairytale characters and the rewards associated with them

- Address the social class and social stratification characteristics that distinguish the poor child from the wealthy child

- Address the notion that those in higher social classes may teach their children about wealth and success from a different social class perspective than the middle class and poor

- Address differences that might exist between the poor child and the wealthy child's concept of money, success and processes involved obtaining them

- And, lastly expose the African American child to a new cadre of stories about Maggie Lena Walker, Joe Dudley, Bob Johnson, John Barfield, Osceloa McCartney, John Sibley Butler, Dennis Kimbro,
Madame CJ Walker, Greg Baranco, Robert Smith, Angel Rich and countless others whose lives reflect true ideas about obtaining money/wealth, success and the processes to obtain them.

\section{Acknowledgement}

The researcher wishes to acknowledge Dr. Hayward Horton and Dr. John Sibley Butler and Dr. Melvin Thomas for their mentoring and support.

\section{Ethics}

This article is original and contains unpublished material. The corresponding author confirms that all of the other authors have read and approved the manuscript and no ethical issues involved.

\section{References}

Ambert, A., 1997. Parents Children and Adolescents: Interactive Relationships and Development in Context. New York: The Haworth Press.

Babbie, E.R., 2016. The basics of social research. California: Wadsworth/Cenage Learning.

Banks-Wallace, J., 2002. Talk that talk: Storytelling and analysis rooted in African American Oral tradition qualitative health. Researcher, 12: 410-426.

Bodenheimer, R., 2019. What Is Critical Race Theory? Definition, Principles and Applications.

Coots, J. F. and H. Gillespie, 1932. Retrieved on July 15, 2019 from http://www.metrolyrics.com/santa-clausis-coming-to-town-lyrics-burl-ives.html

Cosby Show, 2007. Season 3 Episode 08 - Vanessa's Rich. https://www.youtube.com/watch? $v=\mathrm{rO} 35 \mathrm{dhxNjYI}$

Crossman, A., 2019. Content Analysis: Method to analyze social life through words, images.

Deas, G.W., 2011. Take a pause with a Black Santa Claus. New York Amsterdam News 102, Academic Search Complete, EBSCOhost.

Finley, M., 1992. The tooth fairy naked at last. http://www.mfinley.com/poems/toothfairy.htm

Fong, T.P., 2002. The Contemporary Asian American Experience: Beyond the Model Minority. 2nd Edn., New Jersey: Prentice Hall.

Hamlet, J.D., 2011. Word! The African American Oral tradition and its rhetorical impact on American popular culture. Black History Bull., 1: 27-31. Academic Search Complete, EBSCOhost.

Lusted, M.A., 2009. Does Santa Just Sell Stuff? Faces (07491387) 26, MasterFILE Premier, EBSCOhost.

Macionis, J.J., 2018. Sociology. 17 Edn., New Jersey: Prentice Hall-Pearson. 
Manosevitz, M., 1976. Some fantasy characters of young children: An examination of children's beliefs in Santa Claus, the tooth fairy and the Easterbunny. ERIC, EBSCOhost.

Nielsen Company, 2016. Multicultural Influences on Holidays.

Perrucci, R. and E. Wysong, 2008. The New Class Society: Goodbye American Society. 3rd Ed. Lanham: Rowman and Littlefield Publishers.

Principe, G.F. and E. Smith, 2008. The tooth, the whole tooth and nothing but the tooth: how belief in the Tooth Fairy can engender false memories. Applied Cognitive Psychol., 5: 625-642. DOI: $10.1002 /$ acp. 1402

Schneider, N., 2011. From occupy wall Street to occupy everywhere. pp: 13-17.

Strouse, G.A., A. Nyhout and P.A. Ganea, 2018. The Role of Book Features in Young Children's Transfer of Information from Picture Books to Real-World Contexts. Frontiers Psychol.

DOI: $10.3389 /$ fpsyg. 2018.00050
The Red Menace, 2011. Indianapolis Monthly 35, MasterFILE Premier, EBSCOhost.

Vinney, C. 2018. "Understanding Social Identity Theory and Its Impact on Behavior." ThoughtCo, Sep. 28, 2018, thoughtco.com/social-identity-theory4174315 .

Vissing, Y.M., 2008. Psycho-social implications of believing in santa claus. Conference Papers -American Sociological Association 1. SocINDEX with Full Text, EBSCOhost.

Woolley, J.D. and M.E. Ghossainy, 2013. Revisiting the fantasy-reality distinction: Children as naïve skeptics. Child. Develop., 84: 1496-510. DOI: $10.1111 / \mathrm{cdev} .12081$

Wurtzel, N., 2006. The tooth fairy. http://www.toothfairy.org/tooth-fairy-legend.html 